\title{
Correction to: Silicon Photonics Switch Matrices: Technologies and Architectures
}

Francesco Testa, Alberto Bianchi, and Marco Romagnoli

Correction to:

Chapter 12 in: F. Testa, L. Pavesi (eds.), Optical Switching in Next Generation Data Centers, https://doi.org/10.1007/978-3-319-61052-8_12

The chapter was inadvertently published with an error. In page 246 , line 33 , the formula $\mathrm{O}\left[\log _{2} \mathrm{~N}\right]$ is incorrect. It should be $\mathrm{O}\left[\mathrm{N} \log _{2} \mathrm{~N}\right]$. The same has been updated. 